\title{
Factors influencing on residents' household waste separation behavioral intention: Evidence from Ho Chi Minh City, Vietnam
}

\author{
Tran Pham Khanh Toan ${ }^{1 *}$ \\ ${ }^{1}$ People's Committee of District 10, Ho Chi Minh City, Vietnam \\ *Corresponding author: toantpk.19ae@ou.edu.vn
}

\begin{abstract}
ARTICLE INFO
ABSTRACT

DOI: $10.46223 / \mathrm{HCMCOUJS.}$ econ.en.11.1.542.2021

Received: June $12^{\text {th }}, 2020$

Revised: August $19^{\text {th }}, 2020$

Accepted: August $20^{\text {th }}, 2020$

Keywords:

waste separation, behavioral intention, the Theory of Planned Behavior, Ho Chi Minh City

Household solid waste has become a serious problem in Ho Chi Minh City, Vietnam over the last 10 years, resulting in significant side effects on the environment. Although various programs of waste separation at source have been deployed, they have stopped at the level of the pilot - programs and have generally not been replicable. Based on the Theory of Planned Behavior (TPB), this study was examined the key factors influencing waste separation behavioral intention of residents in Ho Chi Minh City (HCMC), Vietnam's economic center. By using SPSS 20.0 software for the sample size of 487 residents, the regression models are used to process and explain data. The research detects six factors, namely Attitude towards waste separation; Social norms; Perceived behavioral control; Knowledge about waste separation; Laws and regulations; Propaganda that significantly directly affected residents 'behavioral intention, Knowledge about waste separation being the strongest construct significantly to predict individuals' intention. Of the six above-listed constructs, only Perceived behavioral control had a negative impact on residents' waste separation behavioral intention. The findings from this research may help policy-makers have a better understanding of residents' waste separation behavioral intention.
\end{abstract}

\section{Introduction}

HCMC is the core of Vietnam's largest urban area, heading towards a population of 12 million in 2025. It is the megacity and the economic center of the country. The economic and industrial development led to massive immigration into HCMC in recent years, causing an average immigration rate of 250.000 people per year from 2007 to 2015 (General Statistics Office of Vietnam, 2014). HCMC is facing a steady increase in the household solid waste volume, and municipal waste takes the main part of the solid waste generated. The total volume of Municipal Solid Waste is estimated at 8.100-8.300 tons/day (excluding waste sludge). It not only causes serious pollution problems, which are not conducive to the environment and human health (Nguyen \& Schnitzer, 2009) but also retards the sustainable development of society.

The concept of separating household solid wastes is not new to Vietnamese people, especially to those living in urban cities such as Hanoi, HCMC, Da Nang City... From 2006 to 2009, the 3R (reduce, reuse, recycle) initiative funded by the Japan International Cooperation 
Agency was implemented by the HCMC Urban Environmental Company in selected central districts (Nguyen, Nguyen, Zhu, \& Le, 2015). The key activities of the 3R initiative included the provision of waste bins, the introduction of new source-separated collection bins, and environmental education for children (Ngo \& Pham, 2011). The government extended the 3R policy and confirmed its determination of increasing the quantity of national waste separation at source and also by implementing the National Strategy on Integrated Solid Waste Management through to 2025. But they have stopped at the level pilot - programs and have generally not been replicable.

Faced with the problem of rapid household solid waste, HCMC authorities have established legislative and institutional groundwork related to waste separation. Based on the Environmental Protection Law 2015 and the Decree No. 38/2015/ND-CP on waste management, HCM authorities issued Decision No.44/2018/QD-UBND dated 14/11/2018 about the regulation on waste separation. However, waste separation in HCMC is currently facing actual difficulties. Residents' unwillingness to sort waste, users' limited awareness and difficulties in sorting waste are among the reasons for arising serious problems of household solid waste in HCMC.

To clarify antecedents and drivers that motivate individuals to separate solid waste, recent studies have employed the Theory of Planned Behavior (TPB) and focused on the impact of motives namely attitude, subjective social norm, and perceived behavioral control on recycling behavior (Ayob, Sheau-Ting, Jalil, \& Chin, 2017; Mahmud \& Osman, 2010). Moreover, several other studies have emphasized the important impacts of situational factors such as past experiences, income, and inconvenience on household waste separating behavioral intention (Desa, Kadir, \& Yusooff, 2011; Philippsen, 2015; Ramayah, Lee, \& Lim, 2012). However, it seems to be that few studies were conducted by exploring the influences of these combined factors on waste separating behavioral intention. Consequently, the need for a more comprehensive picture drawing on related influencers is crucial, which can provide both decision-makers and agencies with an in-depth understanding that can be used to enhance separating rates.

From the research gaps above, it is very urgent and necessary to have a comprehensive study to help understand the social and psychological impacts on residents' behavior toward waste separating, and in moving people on to other pro-environmental behaviors. This study aims to answer the question of what the factors influencing residents' waste separation behavioral intention are.

\section{Literature review}

\subsection{The Theory of Planned Behavior (TPB)}

The Theory of Planned Behavior (TPB) was proposed by Ajzen in 1985. The TPB was extended from the Theory of Reasoned Action (TRA) by adding perceived behavioral control constructs, which is considered one of the most effective socio-psychological models in predicting and explaining social behaviors (Ajzen, 1991). In TPB, the performance of individuals' behavior is determined by their behavior intentions which influenced by three conceptually independent constructs, consisting of attitudes toward behavior (personal attitude and individual conduct), subjective social norm (influence or social pressures to perform a behavior), and perceived behavioral control (indicates individuals' perceived ease or difficulty of performing the particular behavior).

As of its launch, the TPB has been used to explore a wide variety of sustainable behaviors, for instance: sustainable transportation use (Donald, Cooper, \& Conchie, 2014), 
household energy-saving (Webb, Soutar, Mazzarol, \& Saldaris, 2013) and has gained considerable success. It is apparent that TPB is a useful and powerful framework for supporting researches related to sustainable behavior and this approach can be applied to most behaviors (Poškus, 2015). To be specific, there is strong evidence proving that TPB is successful in most research on separating (Ayob et al., 2017; Mahmud \& Osman, 2010); therefore, TPB is now considered as a preferred theory providing a systematical framework for analyzing the determinant elements affecting separation and/or recycling behavior (Ramayah et al., 2012; Tonglet, Phillips, \& Read, 2004).

Recently, researchers have extended the TPB model in several studies about recycling behavior by adding some variables such as recycling experience, laws, and regulations, propaganda ... with the hope to improve the predictability of the model. The reason behind this extension is supposed to have a considerable contribution to sustainable behavior. Following the original TPB, this study adds three latent variables, namely, Knowledge about waste separation, Laws and regulations, and Propaganda, and constructs a model with waste separation intention as a dependent variable to explore the influencing factors of people's intention toward separating household waste. Figure 1 displays the extended theoretical model.

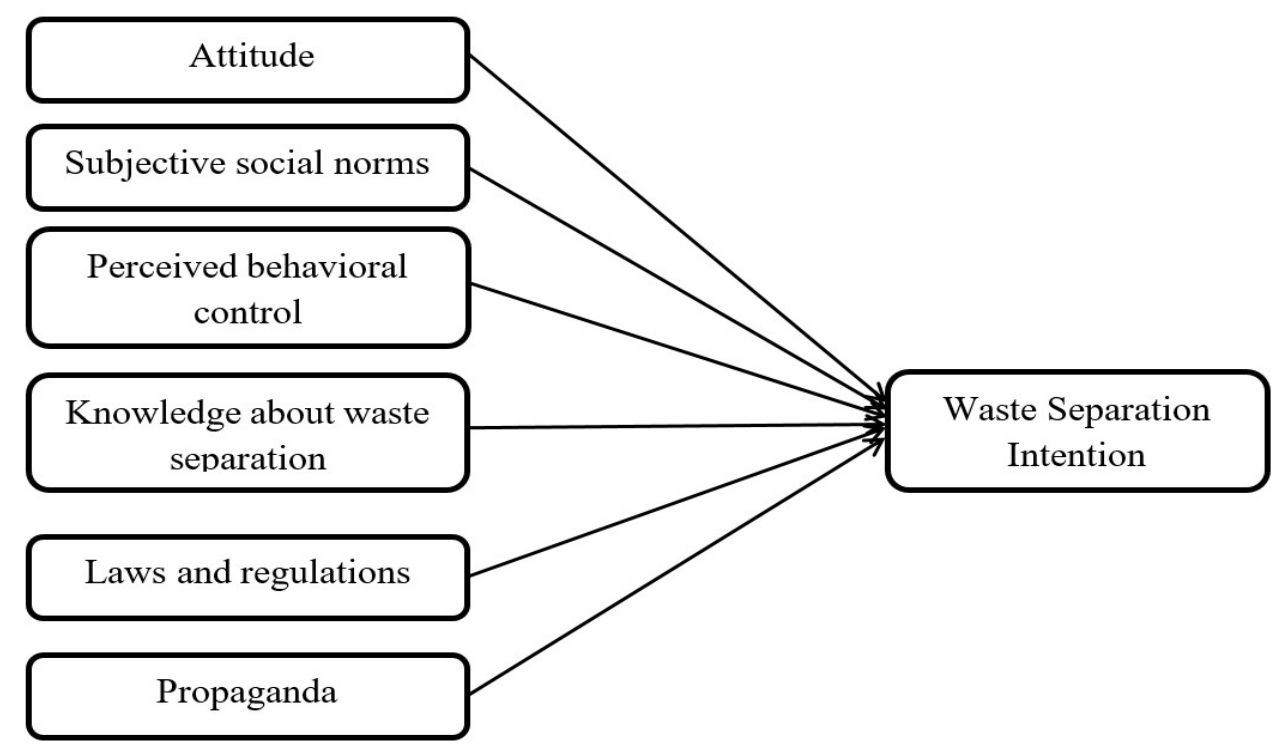

Figure 1. Extended theoretical model

\subsection{Attitude towards waste separation}

Attitude refers to an individual's positive or negative attitude in performing a particular behavior with some degree of favor - disfavor, like-dislike, satisfaction - dissatisfaction, or goodbad polarity (Eagly \& Chaiken, 1993; McEachan, Conner, Taylor, \& Lawton, 2011). As attitude is a relatively persistent and stable psychological construct, many studies have confirmed the influence and prediction of attitude on waste separation behavioral intention (Best \& Mayerl, 2013; Nixon \& Saphores, 2007). This study defines attitude as people's perception and tendencies of behavior toward waste separation. If people hold a positive attitude toward waste separation, then they become more aware of the importance of waste separation and are consequently more intent on engaging in separating waste, and vice versa (Chen \& Tung, 2014). Based on the above discussions, the following hypothesis is proposed. 


\subsection{Subjective social norms}

Subjective social norms are normally supposed to capture the individual's perception of being important to others in his or her social environment wish or expect him or her to behave in a certain way (Ajzen, 1991). In this study, subjective social norms are defined as the approval of others' expectations, such as family norms (Olsen, 2001).

The findings within the literature are mixed, but most studies reported that subjective social norms are an independent and important variable in explaining consumer intention (Ajzen, 1991). Subjective social norms have been shown as an important factor in explaining the motivations toward waste separation in some studies (Ayob et al., 2017; Mahmud \& Osman, 2010).

In the context of East Asian culture, society encourages collectivism rather than individualism. Thus, individuals are easily influenced by leaders and even related organizations. In this study, subjective social norms refer to the influence of external social pressure on the willingness of people to sort waste. The greater the social pressure that people perceive about waste sorting, the stronger their willingness to participate (Matthies, Selge, \& Klöckner, 2012; $\mathrm{Ru}$, Wang, \& Yan, 2018). Thus, the following hypothesis is proposed:

\section{H2: Subjective social norms are positively related to waste separation intention}

\subsection{Perceived behavioral control}

Ajzen (1991) focused on perceived behavioral control as the person's beliefs as to how easy or difficult the performance of the behavior is likely to be. The more resources and opportunities an individual thinks he or she possesses, the fewer obstacles or impediments they anticipate, and the greater should be their perceived control over the behavior. He also suggested that control factors can be either internal to the person (e.g., skills, abilities, power of will, and compulsion) or external to the person (e.g., time, opportunity, and dependence on others). Perceived behavioral control is defined in this study as an integrated measure of internal and external resources that make it easy to act upon the motivation to separate wastes.

Previous studies have proven that the inclusion of perceived behavioral control improves the TPB model's ability to predict or explain intention (Armitage \& Conner, 2001; Verbeke \& Vackier, 2005). However, perceived behavioral control fails to predict intention in quite many cases (Eagly \& Chaiken, 1993; McMillan \& Conner, 2003). Therefore, this study includes perceived behavioral control together with attitudes and social norms and expects that it has a positive effect on intention. Thus, the following hypothesis is proposed:

\section{H3: Perceived behavioral control is positively related to waste separation intention}

\subsection{Knowledge about waste separation}

Knowledge about waste separation is divided into two categories (Zhang, Huang, Yin, \& Gong, 2015). The first one focuses on general knowledge about facts, concepts, and usefulness of waste separation. The second one involves specific waste separation technology (Fryxell \& Lo, 2003). This study defines knowledge about waste separation as general knowledge about waste separation. Knowledge is considered to be one of the key drivers of waste separation. A variety of articles have shown that there is a significant relationship between knowledge about waste separation and waste separation intention (Hansmann et al., 2006; Wang, Guo, \& Wang, 2016).

H4: Knowledge about waste separation is positively related to waste separation intention 


\subsection{Laws and regulations, propaganda}

$\mathrm{Yu}, \mathrm{He}, \mathrm{Li}$, Huang, and Zhu (2014) proved that the laws and regulations had a positive effect on the willingness of residents to separate. Wang et al. (2016) found that promulgation and public spread of the laws and regulations improved environmental awareness among residents and in turn making them ready to sort waste. Noehammer and Byer (1997) founded that compulsory recycling programs launched by the government had a higher participation rate than voluntary resident recycling. Vietnam is a government-leading country which means all levels of government are responsible for issuing legislation on waste separation. In a nutshell, laws, and regulations ruled by the government play a vital part in waste sorting.

Moreover, propaganda could motivate residents to realize the significance of household waste separation and hence perform separate collections better. De Feo and De Gisi (2010) presented the idea that propaganda and citizen encouragement could encourage residents to separate waste. Accordingly, the following research hypothesis can be concluded:

H5: Laws and regulations positively impact waste separation intention

H6: Propaganda is positively related to waste separation intention

\section{Research methodology}

\subsection{Set up the measuring scale and design the questionnaire}

The research is carried out with two main steps: preliminary research and formal research. The preliminary research is performed by in-depth interviews. Ten citizens are invited to engage in face-to-face interviews. This approach is to identify factors that affect waste separation intention. It helps adjust observed variables and measurement scale to a particular situation of waste sorting, as well as related terms. The interviewers use a semi-structured questionnaire that lists the main questions to ask during the interview and which can be changed to make them appropriate to each respondent. Specifically, 29 draft statements of six constructs developed from the literature review are presented to respondents for their assessment. The result of preliminary research shows that almost all factors/variables are rather sufficient, clear, and understandable.

This result directs the design of the quantitative questionnaire for the next step of the research process. The completed scale is built-in Table 1 including Attitude towards waste separation (6 items), Subjective social norm (5 items), Perceived behavioral control (5 items), Knowledge about waste separation (4 items), Laws and regulations (4 items), Propaganda (3 items), and Waste Separation Intention (4 items).

Table 1

Measurement scale of the main constructs

\begin{tabular}{|c|c|c|}
\hline $\begin{array}{l}\text { Item } \\
\text { code }\end{array}$ & Observed variables & Source \\
\hline \multicolumn{3}{|c|}{ Attitude towards waste separation (AT) } \\
\hline AT1 & Waste separation is good & \multirow{4}{*}{$\begin{array}{l}\text { Philippsen } \\
\text { (2015), Ayob } \\
\text { et al. (2017), } \\
\text { focus group } \\
\text { discussion }\end{array}$} \\
\hline AT2 & Waste separation is wise & \\
\hline AT3 & Waste separation is beneficial & \\
\hline AT4 & Waste separation is everyone's responsibility & \\
\hline
\end{tabular}




\begin{tabular}{|c|c|c|}
\hline $\begin{array}{l}\text { Item } \\
\text { code }\end{array}$ & Observed variables & Source \\
\hline AT5 & Waste separation is commendable & \\
\hline AT6 & I am interested in waste separation & \\
\hline \multicolumn{3}{|c|}{ Subjective social Norm (SN) } \\
\hline SN1 & Most people who are important to me support waste separation & \multirow{5}{*}{$\begin{array}{l}\text { Philippsen } \\
(2015)\end{array}$} \\
\hline SN2 & My family thinks that I should do waste separation & \\
\hline SN3 & My friends think that I should do waste separation & \\
\hline SN4 & My colleagues think that I should do waste separation & \\
\hline SN5 & $\begin{array}{l}\text { The people who are doing waste separation that I know always say } \\
\text { good things about this regulation }\end{array}$ & \\
\hline \multicolumn{3}{|c|}{ Perceived behavioral control (PC) } \\
\hline $\mathrm{PBC} 1$ & I have no time for waste separation & \multirow{5}{*}{$\begin{array}{l}\text { Mahmud and } \\
\text { Osman (2010), } \\
\text { focus group } \\
\text { discussion }\end{array}$} \\
\hline PBC2 & Waste separation is difficult & \\
\hline $\mathrm{PBC} 3$ & Waste separation takes too much time & \\
\hline PBC4 & Waste separation is costly for equipment & \\
\hline PBC5 & Waste separation is not easily technically correct & \\
\hline \multicolumn{3}{|c|}{ Knowledge about waste separation (KNO) } \\
\hline KN1 & Waste separation is a primary way to protect the environment & \multirow{4}{*}{$\begin{array}{l}\text { Philippsen } \\
\text { (2015), focus } \\
\text { group } \\
\text { discussion }\end{array}$} \\
\hline KN2 & Waste separation is a primary way to conserve natural resources. & \\
\hline KN3 & I understand how to separate waste & \\
\hline KN4 & I understand the laws and regulations about waste separation & \\
\hline \multicolumn{3}{|c|}{ Laws and regulations (LR) } \\
\hline LR1 & Government policy would influence me to separate waste & \multirow{4}{*}{$\begin{array}{l}\text { Yu et al. } \\
\text { (2014), focus } \\
\text { group } \\
\text { discussion }\end{array}$} \\
\hline LR2 & $\begin{array}{l}\text { The laws and regulations require the responsibilities of residents to } \\
\text { separate waste }\end{array}$ & \\
\hline LR3 & I will obey the laws and regulations about waste separation & \\
\hline LR4 & The laws and regulations & \\
\hline \multicolumn{3}{|c|}{ Propaganda (PP) } \\
\hline PP1 & $\begin{array}{l}\text { Propaganda about waste separation raise the residents' awareness } \\
\text { about waste separation }\end{array}$ & \multirow{3}{*}{$\begin{array}{l}\text { Wang et al. } \\
\text { (2016), focus } \\
\text { group } \\
\text { discussion }\end{array}$} \\
\hline PP2 & Propaganda about waste separation creates motivation to separate & \\
\hline PP3 & $\begin{array}{l}\text { Propaganda about waste separation affect positively to residents' } \\
\text { waste separation intention }\end{array}$ & \\
\hline \multicolumn{3}{|c|}{ Waste Separation Intention (SI) } \\
\hline
\end{tabular}




\begin{tabular}{|c|l|c|}
\hline $\begin{array}{c}\text { Item } \\
\text { code }\end{array}$ & \multicolumn{1}{|c|}{ Observed variables } & \multirow{2}{*}{ Source } \\
\cline { 1 - 2 } SI1 & I intend to separate waste as a habit & \multirow{2}{*}{$\begin{array}{c}\text { Ayob et al. } \\
\text { (2017) }\end{array}$} \\
\cline { 1 - 2 } SI2 & I intend to separate waste if the government supply equipment \\
\cline { 1 - 2 } SI3 & $\begin{array}{l}\text { I am willing to participate in waste separation programs hold by the } \\
\text { government }\end{array}$ & I am willing to tell my relatives about waste separating experiences \\
\cline { 1 - 2 } SI4
\end{tabular}

Source: The researcher's data analysis

The questionnaire in this study includes two main sections, which were designed to fulfill the research objectives and several key requirements from the research hypotheses. The first section focuses on the measurement of the construct in the research model. Questions on attitude towards waste separation, social norms, perceived behavioral control, knowledge about waste separation, laws and regulations, propaganda, and behavioral intentions were included. Studying factors impacting separation behavior intention uses the scale Likert that is 5 levels as follows: level 1: very disagreed; level 2: disagreed; level 3: normal; level 4: agreed; level 5: very agreed. In the second section, questions on demographic characteristics were asked, including gender, age, and education level.

\subsection{Method for choosing sample and sample scale}

The sampling method adopted is convenience sampling. Hair, Black, Babin, and Anderson (2010) emphasize the number of samples must be at least five times the number of observed variables, the result ensures accuracy. Thus, a sample size of 155 or more can be accepted for this research. A total of 500 questionnaires were delivered, and 494 attained samples. After screening and removing invalid questionnaires (those were not fully completed or the answers were one - scale dimension), a total of 487 valid samples were used for further analysis.

\section{Analysis of research result}

\subsection{Descriptive statistics}

Table 2 presents detailed information on respondents' general socio-demographic characteristics. Among the participants, $52.36 \%(n=255)$ were females and $47.63 \%(n=232)$ were males. Most respondents were between 45 to 60 years old $(31,21 \%, n=152)$, followed by above 60 years old $(27,11 \%, n=132)$. Only 83 interviews $(17.04 \%)$ who are under 30 years old.

Regarding the respondents' education level, the high school group accounts for $26.24 \%$, the university or above group accounts for $23.99 \%$. Most of the respondents are a trader (18.89\%), followed by Retiree, Housewife with 90 people (18.48.\%). Thus, the research sample is suitable for research purposes. 
Table 2

Demographic profile of respondents $(n=487)$

\begin{tabular}{|c|c|c|c|}
\hline Demographic Variables & Group & Frequency & Percentage (\%) \\
\hline \multirow{2}{*}{ Gender } & Female & 255 & 52.36 \\
\hline & Male & 232 & 47.63 \\
\hline \multirow{4}{*}{ Age } & $<30$ & 83 & 17.04 \\
\hline & $30-45$ & 120 & 24.64 \\
\hline & $45-60$ & 152 & 31.21 \\
\hline & $>60$ & 132 & 27.11 \\
\hline \multirow{5}{*}{$\begin{array}{l}\text { Educational } \\
\text { level }\end{array}$} & Primary school & 46 & 9.44 \\
\hline & Secondary school & 95 & 19.51 \\
\hline & High school & 128 & 26.28 \\
\hline & $\begin{array}{l}\text { College/Vocational } \\
\text { education }\end{array}$ & 101 & 20.74 \\
\hline & University or above & 117 & 24.03 \\
\hline \multirow{7}{*}{ Profession } & Retiree & 90 & 18.48 \\
\hline & Civil servant & 73 & 14.99 \\
\hline & Office worker & 49 & 10.06 \\
\hline & Trader & 92 & 18.89 \\
\hline & Worker & 39 & 8.01 \\
\hline & Housewife & 90 & 18.48 \\
\hline & Others & 54 & 11.09 \\
\hline
\end{tabular}

Source: The researcher's data analysis

\subsection{Testing for reliability of the scales}

Before testing the hypotheses, we initially test the measurement items for each of the constructs in the model via Cronbach's alpha. The reliability test result shows that all the Cronbach's alpha of the scales is rather high (the minimum of Cronbach's alpha is 0.781), and the item-total correlations of all items are also high (the minimum is 0.513 ), after deleting the items SN4 because of its item-total correlations is $0.288<0.3$. Thus, all measurement items (except for SN4) should be tested using Exploratory Factor Analysis (EFA).

To guarantee convergent validity, items with factor loadings, which are not significant or below 0.5, are eliminated (Bagozzi, 1994). At the first rotated round, six components are extracted and two items are deleted (AT6: I am interested in waste separation and LR2: The laws and regulations require the responsibilities of residents to separate waste) because of low factor loading $(<0.5)$. Table 3 indicates the second round result of exploratory factor analysis based on 28 variables. The six factors of independent variables are extracted at least an Eigenvalue of 1.049 , all factor loadings are higher than 0.5 , ranging from 0.571 to 0.807 . The highest cumulative coefficient is $61.878 \%$. 
Table 3

Factor analysis and reliability

\begin{tabular}{|c|c|c|c|c|c|c|c|}
\hline \multirow{2}{*}{ Construct } & \multirow{2}{*}{ Code } & \multicolumn{6}{|c|}{ Factor loading } \\
\hline & & 1 & 2 & 3 & 4 & 5 & 6 \\
\hline \multirow{5}{*}{$\begin{array}{l}\text { Attitude towards waste } \\
\text { separation (AT) }\end{array}$} & AT2 & .756 & & & & & \\
\hline & AT1 & .707 & & & & & \\
\hline & AT5 & .663 & & & & & \\
\hline & AT4 & .637 & & & & & \\
\hline & AT3 & .622 & & & & & \\
\hline \multirow{5}{*}{$\begin{array}{l}\text { Perceived behavioral control } \\
\text { (PC) }\end{array}$} & PC4 & & .721 & & & & \\
\hline & PC5 & & .700 & & & & \\
\hline & PC2 & & .641 & & & & \\
\hline & PC1 & & .635 & & & & \\
\hline & PC3 & & .564 & & & & \\
\hline \multirow{4}{*}{ Subjective social Norm (SN) } & SN3 & & & .785 & & & \\
\hline & SN5 & & & .742 & & & \\
\hline & SN1 & & & .731 & & & \\
\hline & SN2 & & & .695 & & & \\
\hline \multirow{4}{*}{$\begin{array}{l}\text { Knowledge about waste } \\
\text { separation (KNO) }\end{array}$} & KT1 & & & & .738 & & \\
\hline & KT3 & & & & .675 & & \\
\hline & KT2 & & & & .615 & & \\
\hline & KT4 & & & & .571 & & \\
\hline \multirow{3}{*}{ Propaganda (PP) } & PP2 & & & & & .768 & \\
\hline & PP3 & & & & & .757 & \\
\hline & PP1 & & & & & .736 & \\
\hline \multirow{3}{*}{ Laws and regulations (LR) } & LR4 & & & & & & .807 \\
\hline & LR1 & & & & & & .735 \\
\hline & LR3 & & & & & & .707 \\
\hline $\begin{array}{l}\text { Waste Separation Intention } \\
\text { (SI) }\end{array}$ & SI1 & .747 & & & & & \\
\hline Cronbach's Alpha $=.806$ & SI2 & .775 & & & & & \\
\hline Eigen value $=2.529$ & SI3 & .744 & & & & & \\
\hline Cumulative $\%=63.236$ & SI4 & .760 & & & & & \\
\hline Cronbach's Alpha & & .805 & .781 & .809 & .738 & .809 & .827 \\
\hline Eigen value & & 8.1600 & 1.651 & 1.486 & 1.282 & 1.223 & 1.049 \\
\hline Cumulative \% & & 34.001 & 40.881 & 47.073 & 52.414 & 57.510 & 61.878 \\
\hline
\end{tabular}

Source: The researcher's data analysis 
Waste Separation Intention is uni-dimensional with four observed items. With Varimax rotation of principal component method, only one component is extracted and gets Eigenvalues of 2.529. The KMO coefficient is 0.798 and Barlett's test of sphericity has high significance (Sig. $=0.000$ ). All four-factor loadings are higher than 0.7, and Cronbach's alpha is 0.806 .

\subsection{Correlation analysis}

Correlation coefficients are used to quantify the level of the close relationship between two or more variables. The absolute value of the correlation coefficient closes to 1 when the variables have a tight linear correlation. If the correlation is lower than 0.85 , discriminant validity exists between two variables (John \& Benet-Martinez, 2000). Table 4 summarizes the correlation matrix of six constructs which were analyzed by Pearson with a 2-tailed assumption. The correlation of each pair of constructs is from -0.647 to 0.708 (lower than the conditional index of 0.85 ) which proves that the main constructs gain discriminant validity. Thus, the measurement scale meets the requirement of measuring different constructs.

Table 4

Correlation matrix

\begin{tabular}{|c|c|c|c|c|c|c|c|}
\hline & SI & $\mathbf{P C}$ & KNO & LR & SN & AT & PP \\
\hline SI & 1 & $-.647^{* *}$ & $.708^{* *}$ & $.524^{* *}$ & $.562^{* *}$ & $.602^{* *}$ & $.632^{* *}$ \\
\hline PC & & 1 & $-.548^{* *}$ & $-.419^{* *}$ & $-.418^{* *}$ & $-.547^{* *}$ & $-.536^{* *}$ \\
\hline KNO & & & 1 & $.397^{* *}$ & $.466^{* *}$ & $.500^{* *}$ & $.473^{* *}$ \\
\hline LR & & & & 1 & $.428^{* *}$ & $.476^{* *}$ & $.403^{* *}$ \\
\hline SN & & & & & 1 & $.431^{* *}$ & $.455^{* *}$ \\
\hline AT & & & & & & 1 & $.482^{* *}$ \\
\hline PP & & & & & & & 1 \\
\hline
\end{tabular}

Note: ** Pearson correlation is significant at $\mathrm{p}<0.01$ level (2-tailed)

Source: The researcher's data analysis

\subsection{Multiple regression analysis}

After confirming the acceptability of the measurement model, the estimation of the regression model is performed. The estimated results are shown in Table 5. This table details the results of the multiple regression model to test the relationship between the major factors and waste separation intention. VIF indexes vary from 1.463 to 1.845 (less than 10) and Tolerance indicators are higher than 0.1 , which indicates very low multicollinearity among the variables.

Table 5

Regression analysis

\begin{tabular}{cccccc}
\hline Independent variables & Beta coefficient & t value & Sig. & Tolerance & VIF \\
\hline PC & -.177 & -3.460 & .001 & .542 & 1.845 \\
KNO & .345 & 7.022 & .000 & .586 & 1.706 \\
LR & .115 & 2.530 & .012 & .684 & 1.463 \\
SN & .130 & 2.812 & .005 & .660 & 1.514 \\
AT & .120 & 2.416 & .017 & .570 & 1.753 \\
PP & .211 & 4.386 & .000 & .604 & 1.655 \\
\hline \multicolumn{2}{c}{ Adjusted $\mathrm{R}^{2}=.689$} & F value $=82.297$ & F sig. $=0.000$ \\
\hline
\end{tabular}

Source: The researcher's data analysis 
The adjusted $\mathrm{R}^{2}$ of the regression model of 0.689 implies that $68.9 \%$ of the variance of the dependent variable is generally explained by six independent variables in the model. The Fvalue with significance at $p<0.001$ indicates that the outcome model is very suitable for the collected data, and there is a good fit between the dependent variable and predictors ( $\mathrm{F}$ value $=$ 82.297; F sig. $=0.000$ ). Six independent variables are affecting the dependent variable at a statistically significant level $(\mathrm{p}<0.05)$. There are five factors that affect positively waste separation intention. They are ranked as following orders: Knowledge about waste separation $(\beta 1=0.345)$; Propaganda $(\beta 2=0.211)$; Subjective social norm $(\beta 3=0.130)$; Attitude towards waste separation $(\beta 4=0.120)$; and Laws and regulations $(\beta 5=0.115)$. The factor Perceived behavioral control affect negatively to waste separation intention $(\beta 6=-0.177)$.

The results of relationships between the independent variables and the dependent variable in the regression model lead to the conclusion that the hypotheses $(\mathrm{H} 1, \mathrm{H} 2, \mathrm{H} 3, \mathrm{H} 4, \mathrm{H} 5$, and H6) cannot be rejected.

\section{Conclusions, meanings, and limitations}

The purpose of this study is to extend the Theory of Planned Behavior by including Knowledge about waste separation, Propaganda, and Laws and regulations to explain the intention to separate household waste in HCMC. The findings support all the proposed hypotheses; therefore, this study generates some contributions in both academic and practical fields.

As this study shows, Knowledge about waste separation is the strongest influence on household waste separating intention. Consequently, it is indispensable to build up educational campaigns that may raise people's awareness and beliefs about the benefits of waste sorting in conserving natural resources as well as reducing the use of landfills and emissions of greenhouse gasses. By realizing how beneficial waste separating is, it would motivate residents to sort household waste and further foster these habits among residents.

Besides that, the findings from this study revealed that Propaganda and Attitude towards waste separation are the primary influencing factors in activating residents' household waste separation intention. That shows the fact that those who participate actively in waste separation do so mainly because they understand that waste separation is a cost-effective way of enhancing environmental quality, and increasing socio-economic sustainability. In addition, with regard to the significance of social pressure in developing residents' household waste separation intention. Therefore, public media and communication campaigns should be designed appropriately with the aim to attract more and more people to perform waste sorting behavior.

Moreover, Laws and regulations significantly and positively affect people's intentions toward waste separation. Enforced legislation is one of the best examples of stricter measures that should be put in place to control the waste issue at the point sources, and in this way, it may lead to increased effectiveness of sorting waste rate and encouraging residents' engagement. Laws and regulations which emphasize the incorporation of all relevant stakeholders' responsibilities should be established and implemented in order to contribute to a successful waste separating and management system. First, domestic policies at all levels should be integrated on the basis of these methods and plans. Relevant laws and regulations should be systematized and completed. Second, policy implementation should be strengthened to implement a system of pollution responsibility. Individuals or organizations that refuse to sort of waste should be severely punished.

The result indicating that another important factor that helps to encourage residents to 
participate in household waste sorting is the convenience of sorting. In fact, the result of this study depicts that recycling behavior is impeded by the inconvenience of recycling. Thus, the need for providing the available accessibility of waste collection infrastructure may be put as one of the top priorities and guide people to sort waste properly.

However, some limitations of this study should be noticed. First, the present research is based on a convenience sample from some districts in HCMC so the results cannot represent the whole of the population in HCMC. Future studies should expand to a more representative sample. Second, the extended TPB model has only considered the context of Knowledge, Propaganda, and Laws and regulations. The present investigation is not specifically designed to evaluate factors that are related to habit, cost of classifying waste, and past experience. Next, the study has not measured actual behavior; thus, the gap between intention and future behavior is problematic in inference, and a longitudinal design is encouraged. These problems should be explored in future work.

\section{References}

Ajzen, I. (1985). From intentions to actions: A theory of planned behavior. In J. Kuhl \& J. Beckmann (Eds.), Action-control: From cognition to behavior (pp. 1-39). Heidelberg, Germany: Springer.

Ajzen, I. (1991). The theory of planned behavior. Organizational Behavior and Human Decision Process, 50, 179-211.

Armitage, C., \& Conner, M. (2001). Efficacy of the theory of planned behaviour: Meta-analysis of the theory of planned behavior. British Journal of Social Psychology, 40(4), 471-499.

Ayob, S. F., Sheau-Ting, L., Jalil, R. A., \& Chin, H. C. (2017). Key determinants of waste separation intention: Empirical application of TPB. Facilities, 35(11/12), 696-708.

Bagozzi, R. P. (1994). Measurement in marketing research. In R. P. Bagozzi (Ed.), Principles of marketing research (pp. 1-49.). Cambridge, MA: Blackwell.

Best, H., \& Mayerl, J. (2013). Values, beliefs, attitudes: An empirical study on the structure of environmental concern and recycling participation. Social Science Quarterly, 94(3), 691-714.

Chen, M., \& Tung, P. (2014). Developing an extended theory of planned behavior model to predict consumers' intention to visit green hotels. International Journal of Hospitality Management, $36,221-230$.

De Feo, G., \& De Gisi, S. (2010). Public opinion and awareness towards MSW and separate collection programmes: A sociological procedure for selecting areas and citizens with a low level of knowledge. Waste Management, 30(6), 958-976.

Desa, A., Kadir, N. B., \& Yusooff, F. (2011). A study on the knowledge, attitudes, awareness status and behaviour concerning solid waste management. Procedia - Social and Behavioral Sciences, 18, 643-648.

Donald, I., Cooper, S., \& Conchie, S. (2014). An extended theory of planned behaviour model of the psychological factors affecting commuters' transport mode use. Journal of Environmental Psychology, 40, 39-48. 
Eagly, A. H., \& Chaiken, S. (1993). The psychology of attitudes. Fort Worth, TX: Harcourt Brace Jovanovich.

Fryxell, G. E., \& Lo, C. W. (2003). The influence of environmental knowledge and values on managerial behaviors on behalf of the environment: An empirical examination of managers in China. Journal of Business Ethics, 46(1), 45-69.

General Statistics Office of Vietnam (GSO). (2014). Statistical handbook of Vietnam. Hanoi, Vietnam: GSO.

Hair, J. F., Black, W. C., Babin, B. J., \& Anderson, R. E. (2010). Multivariate data analysis. Englewood Cliffs, NJ: Prentice Hall.

Hansmann, R., Bernasconi, P., Smieszek, T., Loukopoulos, P., Loukopoulos, P., \& Scholz, R. (2006). Justifications and self-organization as determinants of recycling behavior: The case of used batteries. Resources Conservation and Recycling, 47(2), 133-159.

John, O. P., \& Benet-Martínez, V. (2000). Measurement: Reliability, construct validation, and scale construction. In H. T. Reis \& C. M. Judd (Eds.), Handbook of research methods in social and personality psychology (pp. 339-369). Cambridge, UK: Cambridge University Press.

Mahmud, S. N. D., \& Osman, K. (2010). The determinants of recycling intention behavior among the Malaysian school students: An application of theory of planned behavior. ProcediaSocial and Behavioral Sciences, 9, 119-124.

Matthies, E., Selge, S., \& Klöckner, C. A. (2012). The role of parental behaviour for the development of behaviour specific environmental norms - The example of recycling and reuse behaviour. Journal of Environmental Psychology, 32(3), 277-284.

McEachan, R. R. C., Conner, M., Taylor, N. J., \& Lawton, R. J. (2011). Prospective prediction of health-related behaviours with the theory of planned behaviour: A meta-analysis. Health Psychology Review, 5(2), 97-144.

McMillan, B., \& Conner, M. (2003). Applying an extended version of theory of planned behavior to illicit drug use among students. Journal of Applied Social Psychology, 33(8), 1662-1683.

Ngo, C. K., \& Pham, L. P. (2011). Solid waste management associated with the development of 3R initiatives: Case study in major urban areas of Vietnam. Journal of Material Cycles and Waste Management, 13(1), 25-33.

Nguyen, U. N., \& Schnitzer, H. (2009). Sustainable solutions for solid waste management in Southeast Asian countries. Waste Management, 29(6), 1982-1995.

Nguyen, T. H., Nguyen, T. T., Zhu, D., \& Le, N. P. (2015). Factors influencing waste separation intention of residential households in a developing country: Evidence from Hanoi, Vietnam. Habitat International, 48, 169-176.

Nixon, H., \& Saphores, J. D. M. (2007). Financing electronic waste recycling Californian households' willingness to pay advanced recycling fees. Journal of Environmental Management, 84(4), 547-559.

Noehammer, H. C., \& Byer, P. H. (1997). Effect of design variables on participation in residential curbside recycling programs. Waste Management \& Research, 15(4), 407-427.

Olsen, S. O. (2001). Consumer involvement in fish as family meals in Norway: An application of the expectance-value approach. Appetite, 36(2), 173-186. 
Philippsen, Y. (2015). Factors influencing students' intention to recycle (Master's thesis). School of Management and Governance, University of Twente, Netherlands.

Poškus, M. S. (2015). Predicting recycling behavior by including moral norms into the theory of planned behavior. Psychology, 52, 22-32.

Ramayah, T., Lee, J. W., \& Lim, S. (2012). Sustaining the environment through recycling: An empirical study. Journal of Environmental Management, 102, 141-147.

Ru, X., Wang, S., \& Yan, S. (2018). Exploring the effects of normative factors and perceived behavioral control on individual's energy-saving intention: An empirical study in eastern China. Resources Conservation and Recycling, 134, 91-99.

Shi, H., Wang, S., \& Zhao, D. (2017). Exploring urban resident's vehicular PM2.5 reduction behavior intention: An application of the extended theory of planned behavior. Journal of Cleaner Production, 147, 603-613.

Tonglet, M., Phillips, P., \& Read, A. (2004). Using the theory of planned behaviour to investigate the determinants of recycling behaviour: A case study from Brixworth, UK. Resources Conservation and Recycling, 41(3), 191-214.

Verbeke, W., \& Vackier, I. (2005). Individual determinants of fish consumption: Application of the theory of planned behaviour. Appetite, 44(1), 67-82.

Wang, Z., Guo, D., \& Wang, X. (2016). Determinants of residents' e-waste recycling behaviour intentions: Evidence from China. Journal of Cleaner Production, 137, 850-860.

Webb, D., Soutar, G., Mazzarol, T., \& Saldaris, P. (2013). Self-determination theory and consumer behavioural change: Evidence from a household energy-saving behaviour study. Journal of Environmental Psychology, 35, 59-66.

Yu, L., He, W., Li, G., Huang, J., \& Zhu, H. (2014). The development of WEEE management and effects of the fund policy for subsidizing WEEE treating in China. Waste Management, 34(9), 1705-1714.

Zhang, D., Huang, G., Yin, X., \& Gong, Q. (2015). Residents' waste separation behaviors at the source: Using SEM with the theory of planned behavior in Guangzhou, China. International Journal of Environmental Research and Public Health, 12(8), 9475-9491. 